\title{
Diverse wrkforce in hotel industry: A preliminary study of what and why
}

\author{
Supaporn Prasongthan ${ }^{1 *}$, Thitiya Chueaworawit ${ }^{2}$, Pensiri Charoensuk ${ }^{3}$ \\ 1, 2,3 Faculty of Humanities, Kasetsart University, Bangkok, Thailand
}

\section{Keywords \\ Diversity management \\ Hotel industry \\ Human resource management}

Received: 5 October 2018

Accepted: 12 November 2018

Published: 11 December 2018

\begin{abstract}
At present, Diversity Management plays an important role in the organization. Diversity in the workforce can be a competitive advantage because different viewpoints can facilitate unique and creative approaches to product development, problem-solving, and innovation. For Thailand, diversity is quite new. Many organizations overlook the importance of this issue as the hotel business is one of the key businesses in the tourism industry and considers a labor-intensive business that the co-existence of employees from various social-cultural backgrounds. The purposes of this research were 1) to identify major sources of diversity in the hotel business in Bangkok and 2) to examine the diversity management practices of hotels in Bangkok. This study used a qualitative approach. Semistructured interviews were used to collect data from key informants. For data analysis, a coding analysis technique was used. Relationships among codes and themes were then examined. The results showed all ten workforce diversity issues were encountered in hotel business in Bangkok. The challenge issues in diversity management were including marital status/family structure, educational level, cultural/value difference and experience. Interestingly, none of the diversity practice that initiate from the corporate strategic plan or diversity policy were implemented in the sample hotels. Four diversity initiatives were mentioned to use as a tool to manage diversify workforce; training and development, recruitment and selection, labor relation and employee relations, and corporate culture. The suggestions to manage workforce diversity are 1) bringing diversity to be a part of the strategy to lead the organization to success 2) formulating a range of HRM diversity initiative activities to support management strategy and 3) improving communication within organization for better understanding and acceptant of individual differences.
\end{abstract}

\section{INTRODUCTION}

When employees in the organization work together, one thing that is inevitable is diversity, which could be in many areas including gender, age, education, ethnicity, culture, language, people with disabilities, minorities and experiences, etc. The workforce diversity emerged mainly to further the availability equal opportunities in the workplace .This equal opportunity philosophy is aimed at ensuring that the organizations make the most out of the differences from a diverse workforce (Bryan, 1999; Rijal, 2016). The diversity shapes each person's thinking process which resulted into different actions or behaviors. Diversity Management is something that organizations have long been aware of for a long time. Diversity has been incorporated into corporate policy. For a successful global organization, diversity is more than just words, it is something to manage? Because diversity is a powerful tool that will create a competitive advantage with other organizations. Many business leaders are now beginning to believe that diversity has important bottom-line benefits. Diversity in the workforce can be a competitive advantage because different viewpoints can facilitate unique and creative approaches to problem-solving, thereby increasing creativity and innovation which in turn, leads to better organizational performance (R. Allen, Dawson, Wheatley, \& White, 2004; Brunow \& Nijkamp, 2018; Nordin \& Mokhtar, 2015). Diversity requires a type of organizational culture in which each employee can pursue his or her career aspirations without be-

\footnotetext{
* corresponding author: Supaporn Prasongthan

†email: s_prasongthan@hotmail.com
} 
ing inhibited by gender, race, nationality, religion, or other factors that are irrelevant to performance (Bryan, 1999). Diversity management as a management concept has hardly been heard of by most people in developing contries such as China, Indian (Lee \& Saini, 2012) and Thailand. For Thailand, the topic of diversity is quite new and many organizations overlook the important of this issue. As hotel business is one of a key business in the tourism industry and considers as labor intensive business which the co-existence of employees from various social-cultural backgrounds, such as age, race, religion, occupation, identity, gender identity, habitat, life style and other perceptual differences occur. In searching of academic research, there were limited studies available on diversity and diversity management in service industry in Thailand. This study fills this gap through a qualitative approach in order to identify major sources of diversity in hotel business in Bangkok and to examine diversity management practices that have been adopted in hotels in Bangkok.

\section{LITERATURE REVIEW}

\section{Diversity and Diversity Issues}

The difference between people has been acknowledged for long time since Plato, one of the famous Greek philosophers, who wrote the book called the republic that emphasized there are no two people who are born all the same. Later in the nineteenth century, Sir Francis Galton studied and concluded that each person's intellect depends on heredity. Besides, individual differences theory has been developed from the concept of Stimulus-Response that individuals have different personality, attitude, intellect and interest. These differences depend on the social and cultural conditions that stimulus and response into different communication behaviors and exposure choices.

Davis, Frolova, and Callahan (2016) stated that diversity principles have their origins in the American Civil Rights movements of the 1960s. Most significant: the passing of the Civil Rights Act in 1964 which made discrimination unlawful. Following the American example, equal opportunity ideals spread to the rest of the Western world. However, workforce diversity resonates differently across the world due in part to geographic and historical reasons. In general workplace diversity refers to a mosaic of people who bring a variety of backgrounds styles perspectives, values and benefits as assets to the groups and organizations with which they interact (Otike, Messah, \& Mwalekwa, 2010; Oetomo, Satrio, \& Lestariningsih, 2016). The diversity of individuals is divided into two main dimensions; primary dimensions and secondary dimensions. Primary dimensions mean person's condition that has come to birth and affects the entire life including gender, ethnicity, age, sexual orientation, and physical ability, while secondary dimensions, person's condition that could change throughout their life, comprises of education, beliefs/religious, military status, geographic location, income, work background, parental status and marital status (Daft, Murphy, \& Willmott, 2010; Purnamasari \& Fitdiarini, 2016). According to Shen, Chanda, D'netto, and Monga (2009), gender inequality is the oldest and most common diversity issue worldwide. However, the predominant diversity issues in each country are different. In order to understand the diversity factors in various aspects. Nine academic articles were reviewed as a guideline to this study. Ten workplace diversity issues were discovered as shown in Table 1.

TABLE 1. Workplace diversity issues

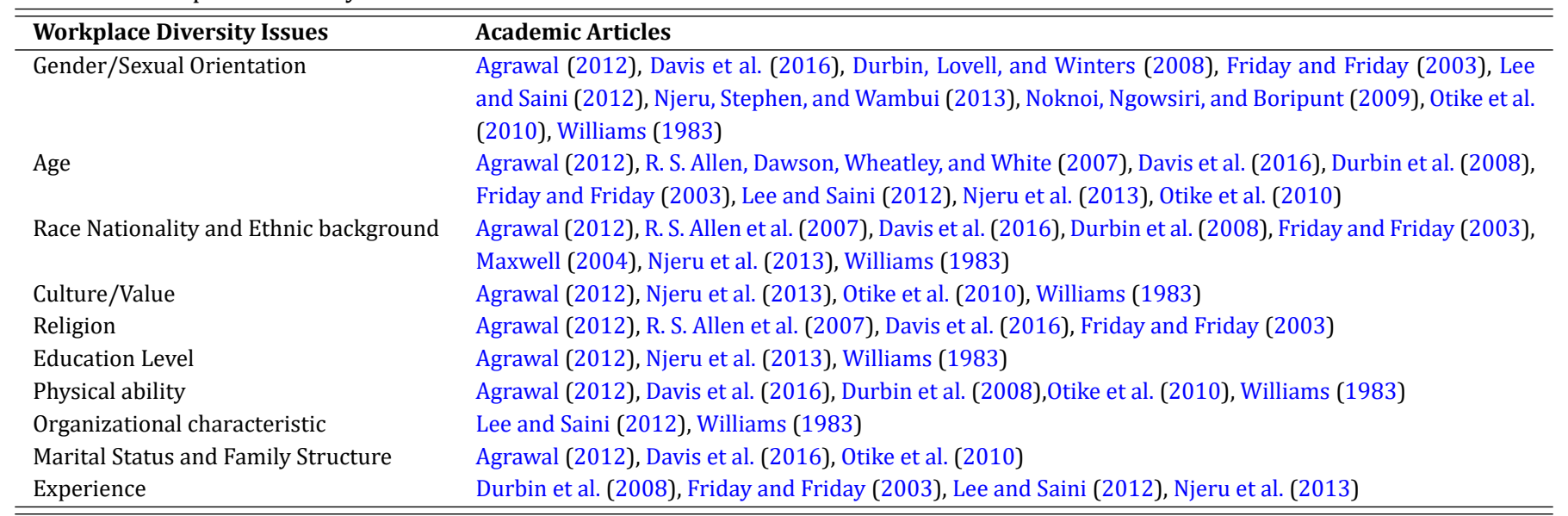




\section{Diversity Management}

Diversity of individuals has an impact on human resource management because organization is a place that combines diverse people in different dimensions in which brings advantages and disadvantages in today's world. These diversities will affect performance, motivation, success, innovation creativity and the interaction of people in the organization which have direct effect on organizational performance. Therefore, creating an atmosphere and corporate culture that allows people to show their talent and the maximum potential is vital. The concept of managing diversity originates from the US as an HR intervention in the mid-1980s. Diversity practices in the area of human resource management were developed to manage diversity effectively. Past studies suggested three dimensions framework of managing diversity consisted of organizational inputs, organizational outcomes and organizational culture (Maxwell, 2004; Na Ayutthaya, Tuntivivat, \& Prasertsin, 2016). Besides using of HRM practices and HR diversity policies were also recommended to manage diverse work groups including recruitment and selection, training and development, performance appraisal and pay (Shen et al., 2009).

Besides, openness in superior-subordinate communication was proposed as one of a solution to attain a more satisfied and motivate diverse workforce (Mahdieh, 2015; Sadri \& Tran, 2002). Managing Personal Growth process (MPG) was used to facilitate discussion on employees' job satisfaction and career development which company can also benefit for improvement in the problematic situation.

Recently, Blancero, Mouriño-Ruiz, and Padilla (2018) suggested ideas of enculturation-acculturation experience management to workforce. Acculturation views as the adoption of and adaption to new cultural patterns that occur when different cultural, ethnic, or racial groups come into contact with each other while enculturation is centered on the maintenance of one's own culture as a result of this cross cultural contact or independent of it (Quintana \& Scull, 2009). Moreover, embracing a bicultural identity may be a key success in diversity management.

\section{METHODOLOGY}

This study used qualitative approach. This approach allowed researcher to explore in details, reflective information and capture a holistic phenomenon. Semi-structure interview technique was used to collect data from five hotels in which were selected through purposive sampling process. The medium-sized hotels and large-sized hotels were targeted due to tendency to have more diverse employee population with formal HR policy and function compared with small organizations (Lee \& Saini, 2012). In selecting hotel business, researcher considered the varieties of hotel in term of ownership, management, size, and hotel brand. A total of five diverse hotels were chosen as following;

Hotel A is the medium-sized hotel with 79 rooms available and considers as 4 stars hotel. It is located in the downtown business area of Bangkok with boutique modern decoration. Hotel A is single unit property not affiliated with any brand and employs 95 Thai employees without expatriate and employee with disability.

Hotel B is the medium-sized hotel with 90 rooms available and considers as 5 stars hotel known as Small Luxury Hotels of the World. It is located on Sukhumvit road, one of important business district in Bangkok. There are five properties owned by the hotel owner with total 440 employees. Human resource manager has responsibility to manage all 5 properties as centralized system. Focusing on Hotel B, there are about 220 Thai employees without expatriate and employee with disability.

Hotel C is the medium-sized boutique hotel with 68 rooms available and considers as 4 stars hotel which located at Khet Phra Nakhon district. Hotel C operates under hotel brand owned by Singapore Hospitality Company. There are many hotel operated under this brand around Asia Pacific including Thailand, Laos, Australia, New Zealand and Singapore. There are 68 Thai employees without expatriate and employee with disability in hotel C.

Hotel D is a large-sized five star luxury hotel owned in part and managed by the largest leading global lodging company. The hotel was officially opened in 2012 and awarded the best design hotel worldwide in 2015. Hotel D features 40 guestrooms with 34 suites, and employs 430 employees with about 5 expatriates and 1 employee with disability. Hotel $\mathrm{D}$ has a unique service culture as a lifestyle brand that markets toward younger and trendier crowds. Hotel E is a large-sized five star luxury hotel with 345 rooms and suites, located in the heart of downtown Sukhumvit area. It is operated under hotel brand owned by multinational hospitality company. There are 455 employees with about 20 expatriates and 4 disable employees. The concept of the hotel brand is a modern luxury hotel blending with artfully. In selecting informants, the management position in human resource department was chosen for an interview because this department was considered as the backbone of the organization which responsible to implement HR practices and ensures employee satisfaction within the organization. Their perception on issues related to workplace diversity and diversity management is a barometer in assessing the 
diversity management climate of the organization (Lee \& Saini, 2012). Researchers have protected the rights of informants by concealed the name of the hotels and interviewees. The face to face interviews were conducted at interviewee's office and lasted generally about 60 minutes. We conducted the interview between August-September 2015. Total 5 informants, two of them are HR manager and HR director. Only one informant is coaching manager that also in charge of HR functions with training and development areas. All informants were asked about their opinion about the issues in hotel diverse workforce based upon ten workplace diversity factors. Moreover, the information about their experience in managing a diverse work groups, the challenges of managing workplace diversity were inquired. For data analysis, transcripts of each conversation are verbatim in order to get the full details. Coding analysis technique was used, with broad open coding categories limited to the ten workplace diversity issues and human resources practices. Triangulation through multiple analysts was employed to conduct the analysis. Relationships among codes and themes were then examined.

The other issue which researcher considers and had been one of the most widely discussed about the optimal number of interview. There is a guideline for determining the number of interviews by the way of data saturation or the point in time when responses no longer reveal 'fresh insights'. On this basis, the researcher considers that a sufficient number of interviews have been conducted when no new themes or stark variations in interviewees' responses are coming to light. In order to achieve validity and reliability of a research, multiple sources of data were collected. Group members share some similar relevant characteristics (e.g., gender, age range, educational level). Moreover, the hotels were chosen from the different types of affiliation and ownership, as well as the size of the hotels range from less than 60 rooms to more than 450 rooms. The triangulation design produced rich productive data that resulted in a validation of results and facilitated and holistic interpretation and understanding of the difference. The use of triangulation is able to minimize the researcher's personal bias and strengthen the validity of findings (Chuang, Church, \& Zikic, 2004).

\section{FINDINGS}

In this section, researcher revealed the findings based on the emerging themes from the data analysis. There are two main parts to be disclosed; Part I Perceived sources of diversity issues and challenges and Part II Diversity management practices.

\section{Part 1: Perceived Sources of Diversity and Challenges in Hotel Business in Bangkok}

Among ten workplace diversity issues that were commonly found, unsurprisingly that all ten workforce diversity issues encountered in hotel business. However, there are five issues that were mentioned as challenges in term hotel sector including marital status and family structure, age difference, level of education and institution, cultural and value difference and work experience.

\section{Marital Status and Family Structure}

All informants mentioned that married employees usually have a higher responsibility than the single employees. Sometimes family matter affects their work schedule. All informants agreed that it is the hotel policy not to select candidate who married to existing employee. However, if employees fall in love and married while they are working in the hotel, human resource department need to make sure that husband and wife are not working at the same department or having conflict of interest:

"Having husband and wife working in the same hotel is challenge because sometimes they have to do the family matters together, for example when wife having baby, husband needs days off to take care of them. When the husband is sick, wife will be absent somehow. These will affect the department operation in term of workforce and co-worker relationship"(HR manager, Hotel B).

"Hotel policy does not allow same family members to work together, especially husband and wife, in order to prevent fraud as well as to prevent the double resignation. This kind of problem happen before in the hotel that the wife having problems with the supervisor or coworker, at the end both of them decided to quit the job without notice at the same time. This problem affected the hotel service standard due to the lack of manpower and caused the problem on hotel's profitability" (HR manager, Hotel C) Age difference. Four out of five informants pointed out that generation gap is the common thing happening in the business nowadays. Generation gap among Baby Boomer, Generation X and Generation $\mathrm{Y}$ typically happened in medium-large company. Besides, having department heads that younger than subordinates is normal and does not have a serious impact on corporate performance because performance appraisal system often based on individual performance over seniority.

"Having younger department heads than subordinates may cause minor problems. Therefore, before being promoted as the head of the department, that person needed to be accepted by other employees. The communication is the key to this problem. Employees must understand the reasons 
for being selected and not selected to that position" (Coaching Manager, Hotel D).

"Younger workers are more likely to quit than older workers because the new generation is bored easily and tend to like challenging job. However, having 3 generations at the workplace is not bad at all, if you can manage and make them understand each other and support each other" $\mathrm{Hu}-$ man Resource Director, Hotel E).

\section{Level of Education and Institution}

Informants from both medium and large hotel (A, C and E) stated that these diversity issues occurred in their properties and somehow caused problem among hotel employees, especially in the back of the house. Housekeeping, kitchen and food and beverage department were pointed out as departments that have diverse workforce in term of educational differences. While, human resources, sale and marketing, and front office department seem not to have this problem, due to the minimum requirement of the job specification. Moreover, informants clarified about the diverse workforce challenges not only happened within department, but also among departments, for example front office agents and housekeeping offices. Based on the job description of these two positions, the requirement of English language skills and educational degree are difference. Therefore sometimes there were conflicts due to the lack of language skills. Surprisingly, the name of institution was considered as the issue that makes them feels difference.

"The diversity issue concerning about education usually happened in the back of the house. Because most of the employees in these departments have bachelor degree, if a department head/supervisor does not have a bachelor's degree, they might doubt about their ability" (Human Resource Manager, Hotel C).

"Some employees are grouped together sorting by their institution. Often, we found that employees who graduated from well-known universities will act more superior than others" (Human Resource Director, Hotel E).

Cultural and value difference. In term of culture difference, informant from hotel D and E which are multinational company and employed number of expatriates said that having diverse nationalities in the hotel is the hotel competitive advantage. Exchanging cultural among employees can increase their cross-cultural understanding. However, there are some challenges for the business on the languages that somehow can be misinterpreted or difficult to understand across languages and culture. Moreover, cultural values on work values between Thai and Westerner are quite different and need to be readjusted.
"Even though our General Manager is Thai, but he grew up abroad and lived there for long time. I could say that he is more likely a Westerner than Thai. He feels that Thai people are inactive. He will try to push and encourage staffs all the time. He meant well to the operation for example the guest complaint that the service in the restaurant was quite slow. The GM will confront this matter direct to the manager and staffs in the restaurant. Some staffs understand that he meant well, but other staffs felt that quite impolite " (HR manager, Hotel C).

"Some of our executives are new to Thailand. They don't understand our culture for example as foreigners they feel that Thai people are Sabai Sabai (easy going), not so productivity and goal oriented. They don't understand why some employees don't go home after work hours. After they stayed for a while, they started to understand that Thai culture to help each other, if friends don't finish their work on time, other tends to stay and help finishing the tasks "(Coaching manager, Hotel D).

Moreover, informant B mentioned that culture differences not only come from variety nationality employees, but also come from Thai employees who come from different regions. "Our employees come from different provinces and regions; therefore, it's unavoidable to have conflicts" (Human Resource Manager, Hotel B).

Year of work experience. Employees with work experience are one of organizational key success because there are many benefits for example developing employability skills, knowledge about work, and attitude toward the service career. However, there is a challenge in case that employee has prior experience from other hotels and adheres to those memories.

"Some employees with experience when they first started working in this hotel, they were confident in their skills on that specific task. They sometimes might think that they work better than current employees. In facts, whenever they enter into the new organization, they need to adjust themselves to the culture and service standard" (Human Resource Director, Hotel A) .

"New employees tend to compare their welfare, benefit and compensation with their previous job. Once they found out about the lower benefit they got, they will spread out these issues that could cause misunderstanding and bad image about the hotel" (HR manager, Hotel C).

\section{Gender, Race, Ethnic, Physical Ability, Organizational Characteristic and Religion Differences}

These diversify issues are common things that happen in Hotel. Having transgender employees working in hotel 
business seem to be normal with about one third of the employees in the hotel. Based on Hofstede's Cultural Dimension Theory, Thais considers having traits of femininity which stress sexuality equality, caring and nurturing behaviors. Moreover, Ministry of Labour has established the Rehabilitation of Legislative Victorian Government (1991) which actively supports the disabled by imposing duties on employers in relation to the employment practices. According to the act, both public and private organizations with more than 100 employees are mandated to hire persons with disabilities in the ratio of one disabled person to every one hundred regular employees (1:100). Employers and business owners complying with their duties are entitled to tax relief as prescribed by law. In special cases, where the organization's workforce consists of $60 \%$ or more disabled employees (employed for more than six months in the fiscal year), a total tax exemption can be claimed. (Royal Thai Government Gazette, 1991) Therefore, for hotels with more than one hundred employees usually employ disabled employees. As for other diversity sources; race, ethnic, religion and organization characteristic, these issues typically occur in hotel business in Bangkok, however it not considers as difficulty or dilemma for organization. We don't have any problem regarding to religion and gender. We respect individual believe and we try to support their daily life routine, for example every day, we have vegetarian and halal food menu" (HR manager, Hotel C).

"No discrimination is one of our brand philosophies. We employed 4 disable employees in our hotel and treat them as normal employees. Also, we believe that differences make better outcomes" (Human Resource Director, Hotel E).

\section{Part 2 Diversity Management Practice within Hotel In- dustry in Bangkok, Thailand}

In order to examine diversity management practices that have been adopted in Hotel in Bangkok, coding analysis technique was used to subdivide the data and categorize in to themes. Surprisingly, none of the diversity practice that initiate from the corporate strategic plan or diversity policy was implemented in the sample hotels. All sample hotels including independent, national and international chain hotels apply existing human resources practices with the activities on diversity initiatives. There are four diversity initiatives that were mentioned to use as a tool to manage diversify workforce; training and development, labour relation and employee relation activities, recruitment and selection and corporate culture.

\section{Training and Development}

Every informant mentioned about using training as a tool to communicate about diverse workforce and to refine and accept individual differences. There are levels of training separating into management training and skills training which each level have different extent of training programs for example language training, cross cultural training and management training. In the global brand hotels, corporate culture training is a crucial because these courses will develop and reinforce employees to have the shared value, attitudes, standards and beliefs that affect an organizational performance. Besides, third language training helps reduce the miscommunication problem among Thai employees and expatriates. As for the potential employees to promote to supervisor and management level, training on supervisory skills and management skills will enhance their ability to communicate, coach, deal with difficulty situation and others. Therefore, diversity training appears likely to continue as an important activity and benefit to organization development (Bendick Jr, Egan, \& Lofhjelm, 2001).

"Even though our GM is Thai, but he could not speak much of Thai language. The Thai language training course helped him to be able to communicate with all staffs starting from the basic every day vocabulary to more complex sentences in which can reduce the miscommunication problem" (HR manager, Hotel C).

"Cross cultural training is very important for our brand because we are the global company that employed more than $100 \mathrm{~K}$ employees worldwide. Therefore, the head office focuses on this issue in order to make smooth and efficient workforce mobility. In case that our employees here have to relocate, they will be able to adjust themselves into other culture easily" (Coaching manager, Hotel D) .

Team building activity was also mentioned from all informants as a tool to encourage collaboration and teamwork as well as help employee to communicate and work better together. Team building also allows employees from different departments of the hotel to get to know each other, and it opens the doors for friendships and break down inequality. Besides, other relationship building activities were brought up during interview. Staff party is one activity that generally occurs in hotel business. It is the event to gather employees, showing appreciation and celebrating the success. Sport day, department party, and department outing were revealed as additional activity to build up unity, commitment and trust. 
"When starting the hotel business, all employees joined the team building activity because we want every one of them to get to know each other in order to work and collaborate well. Right now, we cannot take all employees to go outside the property at once, so we have to split into groups and rotate each group to attend team building activity. Base on our statistical record, we found that team building activities can reduce diversity problem in the hotel because it boost up the employee engagement, employee relations and trust" (Human Resource Director, Hotel A) .

"Outing and staff party are regular event that happen in our hotel. These activities can build employee engagement and unity because employees have change to share ideas about these events. They have fun with these events you will see they started to mingle with other who are from different department or even from different job level" (HR manager, Hotel C).

\section{Labor Relation and Employee Relation}

Healthy work environment can motivate employees to work happily. Employee feedback is one of a great way to communicate critique, comment and suggest about issues happening in organization. In term of diverse workforce, informants claimed that having multi-sources of feedback channel could reduce the problem occurred from individual difference. Considering based upon the organizational behavior levels, starting from organizational level the yearly employee survey has been used as feedback mechanism. Informants from international brand hotel agreed that they apply online survey by third party Company that will generate and conclude results to the regional head office. The final results will be sent to property to analyze and execute the guidelines and procedure to that matter. Comment box is also used as channel to communicate, however not much of the feedback come from this mean.

"Every year, employees need to fill up the online opinion survey. The results will be sent to headquarter in Singapore for the evaluation and then, relay back to office in Bangkok to translate report back to Thai language. The final report will be sent to our property later" (HR manager, Hotel C).

"Human resource department is very welcome for suggestion and troubles happening with all employees. We try to build positive and friendly work environment that employees can directly talk to any HR staff or drop any suggestion in the comment box in front of our department" (Human Resource Director, Hotel A) .

Moreover, informants stated that welfare committee is another effective feedback mechanism. According to Labor Protection Act defined in Section 96, the employer's busi- ness establishment that has employed 50 people needs to provide welfare committee in place operations in order to promote bilateral system to discuss between employee and employer regarding welfare support. The committee comprises of selected employee representatives from various departments and could be from any position level. The committee will have monthly meeting discussing about develop welfare model required by law and beyond the law, support and promote actions, and hear information from employee's commentary or suggestions.

Another communication activity that four informants mentioned is meeting with general manager. Informants claimed that an informal meeting with board can foster understanding and improve communication and give employees the opportunity to interact with GM. Several forms of informal meeting were conducted within national and international chain hotel such as Lunch with GM, GM Early bird, Town hall meeting and associate meeting. Having employees meet with executive staff in informal surroundings has plenty of beneficial because these face to face, two way communication sessions give opportunity for both employee and employer to communicate and give feedback directly. "GM lunch and GM Early bird activities are pre-arrange informal sessions to allow employees at all level to have a change to talk, discuss and even complaint to the GM. These activities are our brand requirement to fill the gap between executives and employees. I remember one employee complaint about inequality about hotel parking space that only allow free parking for management level. This issue had been discussed over the executive board, at the end even though hotel could not provide parking space for all employees. The final decision has been broadcasted to all employees in order to clarify reasons and better understanding (Human Resource Director, Hotel E) .

As for team and individual level, different type of diversity can have both positive and negative impact on team performance. Employee relations become key success in managing diverse work team because effective employee relations could assist communication between employees and supervisors, and provide counsel and advice regarding diversity related inquiries. Supervisor or manager as team leader have responsibilities to support manage and develop team member and build relationship internally. Informants reviewed that providing supervisory training program that include leadership development, problem solving technique and cross cultural communication could help working effectively across differences.

"Our hotel have Good and Gift Committee which responsible to look after employee's welfare and benefit. After 
each monthly meeting, human resource department as part of the committee has to submit the meeting report to the board of directors meeting" (Human Resource Director, Hotel A).

"We launched hotel employee experience application on the smart phone's applications, employees require to install this to their phone in order to provide suggestion, comment, and complain. These feedbacks will be discussed over the welfare committee meeting. We used to deal with cases about complaining on canteen space and establishment of employee fitness center. Due to the hotel structure, the area of our property is quite compact with about 1 Rai (0.39 Acre). Expanding areas in property is very difficult and requires investment fund. Therefore, our boards agree to provide fitness membership card to employees to attend nearby fitness center" (HR manager, Hotel C).

\section{Recruitment and Selection}

According to labour protection act B.E. 2541 section 15, an employer shall treat male and female employees equally in employment unless the description or nature of work prevents such treatment. As the result, hotel recruitment and selection policy is to ensure that recruitment and selection decisions are based on the ability of the applicant to meet the requirement of the job description and specification of relevant position. Also, the policy is intended to make sure that all applicants will be treated fairly. All informants suggested that in selection process, the organizations looked for the right people in term of positive attitude over the educational level or institution. Moreover evidence continues to suggest that in single unit property, national and international chain hotels often believe that they can easily train people for skills but quite difficult to change their attitude. Selecting right people in term of positive attitude can reduce conflict that might happen from diverse workforce.

"In selection process, the selected candidates will be chosen base upon general requirements of position. The final round of the selection usually based upon their attitude. Individual attitude is very hard to change or even hard to refine. We believe that positive attitude can reduce work conflict and make an organization successful " (HR manager, Hotel C).

"In order to solve problem occur from diversity, you have to focus on the source of the problem, which is "Employee". Therefore, in selection process, you have to choose the candidate with positive attitude, optimistic, and having his/her goal that align with the organization direction. So that, when they start working with hotel, less trouble would turn out"(Human Resource Director, Hotel E).

\section{Organizational Culture}

Organizational culture is a characteristic of an organization which is rooted in the values, belief and assumptions held by organizational members. Chuang et al. (2004) defined organizational culture as the pattern of shared value which maintain as a bounded unit and provide it with a distinct identity as well as shaped diverse group functioning. Culture of unity was mentioned from informants as an approach to reduce dissimilar individuals or groups. Culture of respect and trust was also affirmed from informants as the way to demonstrate acceptance of differences. Lastly, building culture of belonging that value each individual and their contribution to the organizational goals is one of the most important compositions to manage diversity. Creating appropriate corporate culture could reflect patterns of beliefs and values among employees to understand and respond to coworkers who are different from them.

"We value culture of unity because this culture shapes up all five properties employees to be as one. Besides, the sense of belonging is another key issue to make acceptance among employees or team. Once they feel that they belong to the hotel, the performance and the loyalty level will go upward "(Human Resource Manager, Hotel B).

"Our hotel characteristic is quite unique and different from other luxury hotel. Our customer target groups are young chic and trendy, therefore our culture is respect for individuality. We accept the fact that they are individual and respect them for it" (Coaching manager, Hotel D).

\section{DISCUSSION AND CONCLUSION}

Diverse workplace nowadays seems to be typical thing happening in organization, especially medium-large sized company. The predominant diversity issues in each country are different (Shen et al., 2009). For hotel industry in Bangkok, Thailand, results found several aspects of diversity sources including gender, age, race, cultural/value, religion, education, physical ability, family status, experience and organizational characteristic. However, there are five issues that were mentioned as challenges in term hotel sector including marital status and family structure, age difference, level of education and institution, cultural and value difference and work experience. Similarly to Chinese workforce, cultural differences were developed into challenges from both expatriates and local employee (Lee \& Saini, 2012). While other countries faced gender inequality which is the most common diversity issue worldwide, hotel industry in Bangkok was somehow different. The level of acceptance on individual sexual orientation is high, so that the ratio of male, female and transgender hotel employee is about the same. As 
diversity in workplace is essential to business growth, creativity and innovation, diversity management has become hot issue for organizations nowadays. The results demonstrated diversity practices involved in hotel industry including training and development, labour relation, recruitment and selection, and organizational culture. In order to implementing these practices effectively, the bottom line of efficient communication and acculturation require to be recognized and appreciated. Surprisingly, none of the diversity practices initiating from the corporate strategic plan or diversity policy. All sample hotels including independent, national and international chain hotels applied existing human resources practices with the activities on diversity initiatives which comply to Shen et al. (2009) reviewing that HRM functions have considerable overlap with diversity management since both approaches hinges on strategic thinking and people centered policies. Four diversity initiatives were mentioned to use as a tool to manage diversify workforce; training and development, recruitment and selection, labor relation and employee relations, and corporate culture. Considering based upon the organizational behavior levels, starting from organizational level, organizational culture, recruitment and selection policy, employee survey, comment box and welfare committee can be used as effective tools to value and harness workforce differences. As for team and individual level, different HRM initiatives can be applied such as team building activity, training courses, staff party and associate meeting. Reflecting the results above, the strategic level require to acknowledging, valuing and managing workforce diversity. A management philosophy that recognizes diversity is critical for organizational success (Shen et al., 2009).

\section{Implications \& Limitations}

Based on results the suggestions to manage workforce diversity are 1) bringing diversity to be a part of the strategy to lead the organization to success 2 ) formulating a range of HRM diversity initiative activities to support management strategy and 3) improving communication within organization for better understanding and acceptant of individual differences. Whilst filling research gap, this study has some limitations. First, small sample size due to the fact that the time limitation of the study. Another limitation was the generalization of the study as limited to a case study. Therefore, further study cam be done in scope of hotel sector nationally or other sectors. Such study would provide bigger picture of perceived sources of diversity and advance our understanding of the diversity management.

\section{REFERENCES}

Agrawal, G. P. (2012). Fiber-optic communication systems. New York, NY: John Wiley \& Sons.

Allen, R., Dawson, G., Wheatley, K., \& White, C. S. (2004). Diversity practices: Learning responses for modern organizations. Development and Learning in Organizations: An International Journal, 18(6), 13-15. doi:https://doi.org/10.1108/ 14777280410564185

Allen, R. S., Dawson, G., Wheatley, K., \& White, C. S. (2007). Perceived diversity and organizational performance. Employee Relations, 30(1), 20-33. doi:https://doi.org/10.1108/01425450810835392

Bendick Jr, M., Egan, M. L., \& Lofhjelm, S. M. (2001). Workforce diversity training: From anti-discrimination compliance to organizational development. Human Resource Planning, 24(2), 45-50.

Blancero, D. M., Mouriño-Ruiz, E., \& Padilla, A. M. (2018). Latino millennials-the new diverse workforce: Challenges and opportunities. Hispanic Journal of Behavioral Sciences, 40(1), 3-21. doi:https://doi.org/10.1177/0739986317754080

Brunow, S., \& Nijkamp, P. (2018). The impact of a culturally diverse workforce on firms' revenues and productivity: An empirical investigation on Germany. International Regional Science Review, 41(1), 62-85. doi:https://doi.org/10 $.1177 / 0160017616642820$

Bryan, J. H. (1999). The diversity imperative managing people welt is the top priority. Executive Excellence, 16(3), 6-6.

Chuang, Y.-T., Church, R., \& Zikic, J. (2004). Organizational culture, group diversity and intra-group conflict. Team Performance Management: An International Journal, 10(1/2), 26-34. doi:https://doi.org/10.1108/13527590410527568

Daft, R. L., Murphy, J., \& Willmott, H. (2010). Organization theory and design. New York, NY: Cengage learning EMEA.

Davis, P. J., Frolova, Y., \& Callahan, W. (2016). Workplace diversity management in Australia: what do managers think and what are organisations doing? Equality, Diversity and Inclusion: An International Journal, 35(2), 81-98. doi:https:// doi.org/10.1108/edi-03-2015-0020

Durbin, S., Lovell, L., \& Winters, J. (2008). Diversities in an organisational context. Equal Opportunities International, 27(4), 396-400. doi:https://doi.org/10.1108/02610150810874340 
Friday, E., \& Friday, S. S. (2003). Managing diversity using a strategic planned change approach. Journal of Management Development, 22(10), 863-880. doi:https://doi.org/10.1108/02621710310505467

Lee, C. F., \& Saini, D. S. (2012). Managing diversity in Chinese and Indian organizations: A qualitative study. Journal of Chinese Human Resources Management, 3(1), 16-32. doi:https://doi.org/10.1108/20408001211220548

Legislative Victorian Government. (1991). Disability services act 1991. Retrieved from https://bit. Iy/2ShWDaQ (accessed on 14 June, 2017)

Mahdieh, 0. (2015). Interaction between communication and organizational conflict and its relationship with performance. International Journal of Business and Administrative Studies, 1(2), 54-60. doi:https://doi.org/10.20469/ijbas.10002-2

Maxwell, J. A. (2004). Causal explanation, qualitative research, and scientific inquiry in education. Educational Researcher, 33(2), 3-11. doi:https://doi.org/10.3102/0013189x033002003

Na Ayutthaya, J. S., Tuntivivat, S., \& Prasertsin, U. (2016). The effect of positive psychological capital and organizational climate on service quality: The mediation role of work engagement of hotel service employees in Ratchaburi province. Journal of Administrative and Business Studies, 2(4), 167-176. doi:https://doi.org/10.20474/jabs-2.4.3

Njeru, N., Stephen, M., \& Wambui, M. (2013). Analysis of factors influencing formulation of strategic plans in Embu North District, Embu County, Kenya. Global Business and Economics Research Journal, 2(5), 116-129. doi:https://doi.org/ 10.15580/gjas.2017.8.100117141

Noknoi, C., Ngowsiri, S., \& Boripunt, W. (2009). Have debit cards changed thai consumer behavior? International Journal of Marketing Studies, 1(2), 151-150. doi:https://doi.org/10.1108/02610150810874340

Nordin, S., \& Mokhtar, M. (2015). Discussion: Diversity in Malaysia new media art. International Journal of Business and Administrative Studies, 1(3), 94-98. doi:https://doi.org/10.20469/ijbas.10003-3

Oetomo, H. W., Satrio, B., \& Lestariningsih, M. (2016). The leadership style as moderating, influence of compensation, Organizational Citizenship Behaviour (OCB), and stress towards intention to quit. International Journal of Business and Economic Affairs, 1(1), 6-12. doi:https://doi.org/10.24088/ijbea-2016-11002

Otike, W., Messah, B., \& Mwalekwa, K. (2010). Effects of workplace diversity management on organizational effectiveness: A case study. European Journal of Business Management, 4(8), 45-70.

Purnamasari, K., \& Fitdiarini, N. (2016). Corporate diversification and cash holding. Journal of Administrative and Business Studies, 1(1), 21-27. doi:https://doi.org/10.20474/jabs-1.1.4

Quintana, S. M., \& Scull, N. C. (2009). Latino ethnic identity. In Villarruel, F. A., Carlo, G., Grau, J. M., Azmitia, M., Cabrera, N. J. \& Chahin, T. J., (Eds.), Handbook of U.S. latino psychology: Developmental and community based perspectives. Thousand Oaks, CA: SAGE.

Rijal, S. (2016). The influence of transformational leadership and organizational culture on learning organization: A comparative analysis of the IT sector. Journal of Administrative and Business Studies, 2(3), 121-129. doi:https://doi.org/ $10.20474 /$ jabs-2.3.3

Sadri, G., \& Tran, H. (2002). Managing your diverse workforce through improved communication. Journal of Management Development, 21(3), 227-237. doi:https://doi.org/10.1108/02621710210420291

Shen, J., Chanda, A., D'netto, B., \& Monga, M. (2009). Managing diversity through human resource management: An international perspective and conceptual framework. The International Journal of Human Resource Management, 20(2), 235-251. doi:https://doi.org/10.1080/09585190802670516

Williams, G. (1983). Managing diverse work groups: The implications for management education. Leadership \& Organization Development Journal, 4(1), 20-25. doi:https://doi.org/10.1108/eb053524 